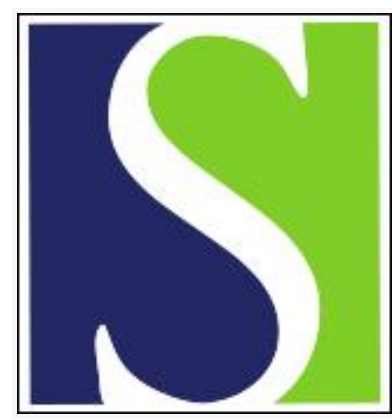

Scand J Work Environ Health 2006;32(5):339-348

https://doi.org/10.5271/sjweh.1029

Issue date: 31 Oct 2006

Do burned-out and work-engaged employees differ in the functioning of the hypothalamic-pituitary-adrenal axis?

by Langelaan S, Bakker AB, Schaufeli WB, van Rhenen W, van Doornen LJP

Affiliation: Utrecht University, Department of Social \& Organizational Psychology, PO Box 80.140, 3508 TC Utrecht, Netherlands. saar.langelaan@tno.nl

Refers to the following text of the Journal: 2001;27(4):279-286

The following article refers to this text: 2006;32(5):333-337

Key terms: burned-out employee; burnout; cortisol awakening response; dehydroepiandrosterone-sulfate; dexamethasone suppression test; function; hypothalamic-pituitary-adrenal axis; work engagement; work-engaged employee

This article in PubMed: www.ncbi.nlm.nih.gov/pubmed/17091201 


\title{
Do burned-out and work-engaged employees differ in the functioning of the hypothalamic-pituitary-adrenal axis?
}

\author{
by Saar Langelaan, MSc, ${ }^{1,2}$ Arnold B Bakker, PhD, ,, 3 Wilmar B Schaufeli, PhD, , 2 Willem van Rhenen, \\ MSc, ${ }^{4}$ Lorenz JP van Doornen, $P h D^{2,5}$
}

\begin{abstract}
Langelaan S, Bakker AB, Schaufeli WS, van Rhenen W, van Doornen LJP. Do burned-out and work-engaged employees differ in the functioning of the hypothalamic-pituitary-adrenal axis? Scand J Work Environ Health 2006;32(5):339-348.
\end{abstract}

\begin{abstract}
Objectives The central aim of the present study was to examine differences in the functioning of the hypothalamic-pituitary-adrenal (HPA) axis between 29 burned-out, 33 work-engaged, and 26 healthy reference managers, as identified with the Maslach Burnout Inventory-General Survey and the Utrecht Work Engagement Scale.

Methods All of the managers were employed in a large Dutch telecommunications company. Salivary cortisol was sampled on three consecutive workdays and one nonworkday to determine the cortisol awakening response. Salivary dehydroepiandrosterone-sulfate (DHEAS), a cortisol counterbalancing product of the HPA axis, was measured on these days 1 hour after managers awakened. The dexamethasone suppression test was used to investigate the feedback sensitivity of the HPA axis.

Results The morning cortisol levels were higher on the workdays than on the nonworkday, but this effect did not differ between the three groups. The burned-out, work-engaged, and reference groups did not differ in the cortisol and DHEAS levels, the slope of the cortisol awakening response, and the cortisol: DHEAS ratio. The work-engaged group showed a stronger cortisol suppression in response to the dexamethasone suppression test than the other two groups, the finding suggesting higher feedback sensitivity among work-engaged managers. Conclusions Burned-out and work-engaged managers only differ marginally in HPA-axis functioning.
\end{abstract}

Key terms burnout; cortisol awakening response; dehydroepiandrosterone-sulfate; dexamethasone suppression test; work engagement.

Recent studies have expanded burnout research by focusing on its presumed opposite, work engagement (1$3)$. Burnout is a reaction to chronic occupational stressors and insufficient recovery $(4,5)$ and is characterized by exhaustion, cynicism, and reduced professional efficacy (5). In contrast, work engagement is strongly associated with job resources and is defined as a positive, fulfilling state of mind. Work engagement is characterized by vigor (high levels of energy while working, willingness to invest effort in work, and persistence in the face of difficulties), dedication (sense of enthusiasm, inspiration, pride, and challenge), and absorption (being fully concentrated and happily engrossed in one's work) (3). Vigor and dedication are the direct positive opposites of exhaustion and cynicism, respectively (2, $6)$.

Burnout is positively associated with illness and disease, including myocardial infarction (7), common cold (8), and type 2 diabetes (9). To the extent that work engagement is the opposite of burnout, one may assume that work engagement is associated with positive health outcomes. Indeed, it has been reported that work-engaged employees seem to enjoy good mental and psychosomatic health (1). Any association between wellbeing (burnout and work engagement) and physical health status is presumably mediated by (stress) physiological mechanisms, the main candidate being the hypothalamic-pituitary-adrenal axis (HPA axis), which

1 Department of Social and Organizational Psychology, Utrecht University, Utrecht, Netherlands.

2 Research School Psychology and Health, Utrecht University, Utrecht, Netherlands.

3 Institute of Psychology, Erasmus University Rotterdam, Rotterdam, Netherlands.

4 ArboNed Utrecht, Utrecht, Netherlands.

5 Department of Health Psychology, Utrecht University, Utrecht, Netherlands.

Reprint requests to: S Langelaan, Utrecht University, Department of Social \& Organizational Psychology, PO Box 80.140, 3508 TC Utrecht, Netherlands. [E-mail: saar.langelaan@tno.nl] 
regulates the long-term adaptation of organisms to stress. Consistent with this view, changes in HPA-axis functioning have been observed in many stress-related disorders, for example, (vital) exhaustion (10), the chronic fatigue syndrome (11), post-traumatic stress disorder, and depression (12).

Disruptions in HPA-axis functioning, due to chronic stress, are usually examined by investigating the level and course of cortisol during the day and the cortisol awakening response. The cortisol awakening response is the acute increase of the cortisol level in the $30 \mathrm{~min}$ utes after awakening. It has shown to be independent of the general cortisol level and thus provides independent information on HPA-axis functioning (13). Because the cortisol awakening response reflects the capacity of the adrenal cortex to produce cortisol, the measure is considered to be an indicator of HPA axis (re)activity (13). A strong cortisol awakening response is generally associated with chronic work stress (14-16), the main precursor of burnout.

Unfortunately, so far, researchers have paid little attention to the psychophysiological correlates of burnout and work engagement. The studies that did examine HPA-axis functioning in burnout reported inconsistent results (17-23), and, to date, there are no studies that have examined HPA-axis functioning in work engagement. The central aim of our study was to examine psychophysiological differences, as measured by HPAaxis functioning, between employees high in burnout and their counterparts, high in work engagement.

In chronically stressed or burned-out employees who are not on sick leave, elevated cortisol levels during the first hour after awakening (16) and during the workday (20) have been reported, as well as lowered morning cortisol levels (23). Other studies have shown, however, no deviations in cortisol in burned-out persons (18) and employees who are confronted with high job strain (24). In clinical burned-out groups (eg, people on sick leave who received a clinical burnout diagnosis and who attended psychotherapy for their complaints) the same inconsistencies have been found. Both lowered $(21,25)$ and elevated cortisol levels during the first hour after awakening $(17,19)$ have been reported. Furthermore, there seemed to be no differences in cortisol levels between burnout patients and a healthy reference group during the day (17). The most recent and extensive study showed that the cortisol awakening response and the diurnal cortisol course did not differ between a clinical burn-out group and a healthy, matched reference group (22).

Remarkably, in studies on other stress-related disorders that have the exhaustion component in common with burnout, like vital exhaustion (10) and chronic fatigue syndrome (11), lower cortisol levels have often been reported. This finding led some scholars to argue that more attention should be paid to the hypoactivity of the HPA axis in stress-related bodily disorders (12, 26). In short, the overall picture is confusing, and it is hard to predict what is to be found in stress-related disorders, either hypo- or hyperfunction of the HPA axis. Adding to this confusion are the observations that positive well-being $(27)$ and positive affect $(28,29)$ have been associated with lower cortisol levels as well. This finding would imply that work engagement may be associated with lower cortisol levels.

However, cortisol levels give only a partial picture of HPA-axis functioning. To complete the picture, we used two other indicators in our present study. First, we included the dexamethasone suppression test, which provides information about the feedback sensitivity of the HPA axis $(22,30)$. Cortisol regulates its own level by exerting a negative feedback function on the hypothalamus and hypophysis and thereby inhibits the synthesis of corticotropin-releasing hormone (CRH) and adrenocorticotropic hormone (ACTH) and thus also the synthesis of cortisol by the adrenal cortex. This phenomenon is called the negative feedback loop of the HPA axis. Dexamethasone is a synthetic cortisol and mimics the negative feedback effect of cortisol. Its application inhibits own-body cortisol synthesis. The extent to which cortisol release is inhibited after dexamethasone intake is a measure of the feedback sensitivity of the HPA axis. Both studies that have used the dexamethasone suppression test with burned-out persons yielded conflicting results. One reported lowered morning cortisol levels in burnout after dexamethasone intake (23), and the other found no differences between a clinical burnout group and a healthy reference group after dexamethasone intake (22).

Second, it is potentially promising to examine another product of the HPA axis, dehydroepiandrosteronesulfate (DHEAS), which is considered to antagonize the effects of cortisol. DHEAS is the sulfated form of DHEA and circulates in the blood in relatively large quantities (about 10 times that of cortisol). It has a long biological half-time (7-10 hours) and displays a weak circadian rhythm (31). Higher levels of DHEA(S) have been shown to be positively associated with positive affect (32), positive well-being, and better physical and mental health (33), whereas lower DHEAS levels have been found in depression $(34,35)$ and in chronic fatigue syndrome (35-37). It can thus be expected that work engagement is positively associated with DHEAS levels and negatively associated with burnout. However, the only study that investigated DHEAS levels in relation to different levels of burnout reported no differences between a high- and a low-burnout group (18).

Due to their antagonistic relationship, the cortisolto-DHEAS ratio is considered a parameter of interest. A metabolic shift of DHEAS production (androgen) to 
cortisol production (glucocorticoid) has been found to be associated with illnesses and chronic stress $(38,39)$ and might thus be associated with burnout as well. On the other hand, work engagement may be associated with a shift towards androgen production.

The aim of our study was to combine in one and the same study the opposite poles of work-related well-being, burnout and engagement, with the opposite roles of cortisol and DHEAS in the stress physiological realm.

\section{Study population and methods}

\section{Study population and procedure}

A total of 88 male managers participated in this study (table 1). These men were selected from a larger sample of managers ( $\mathrm{N}=338$ ), employed at a Dutch telecommunications company. An extensive periodic employee health and well-being survey was carried out in this company by an occupational health service. The survey was sent by surface mail, along with a cover letter, to the home addresses of 450 managers, of which 338 returned the completed survey in a prestamped envelope (response rate 75\%). In the cover letter, the managers were asked to contact the occupational health service to make an appointment with the occupational health physician, who provided personal feedback on the survey. The participants did not receive any monetary reward for participation but were freely offered a general medical health check about which they also received feedback. During their feedback meeting, the managers were invited to participate in the study if their scores on the Maslach Burnout Inventory-General Survey (MBI-GS) and the Utrecht Work Engagement Scale (UWES) met externally validated criteria $(40,41)$. The managers were excluded if they used corticosteroids, had asthma, diabetes, rheumatoid arthritis, cardiovascular disease, metabolic or endocrinological abnormalities, had a body mass index of $>30 \mathrm{~kg} / \mathrm{m}^{2}$, or if they used alcohol and drugs excessively. All of these factors potentially influence cortisol.

The managers were assigned to the burned-out group when their individual score on the burnout questionnaire
(MBI-GS) met the following inclusion criteria (41): (i) exhaustion $\geq 2.2$ and (ii) either cynicism $\geq 2.0$ or personal accomplishment $\leq 3.66$. Twenty-nine managers fulfilled these criteria. Recently, the validity of these cut-off scores has been demonstrated (42). The managers who scored higher than 4.67 (ie, mean sum of all 17 items) on the engagement questionnaire (UWES) were assigned to the work-engaged group $(\mathrm{N}=33)(40)$. The reference group $(\mathrm{N}=26)$ consisted of managers with an individual score according to the following inclusion criteria: burnout questionnaire (MBI-GS): exhaustion $\leq 1.5$, cynicism $\leq 1.0$ and personal accomplishment $>3.66$; the engagement questionnaire (UWES): mean score $\leq 4.67$.

The managers who were willing to participate signed an informed consent at the feedback meeting and received a package with an instruction letter, the salivettes, and a short diary to keep a record of their saliva sampling. They were instructed to conduct the sampling the following week and were asked to return the saliva samples and the diary by surface mail to the researchers. The university ethics committee approved of the study.

\section{Psychological measures}

Burnout was measured with the Dutch version (41) of the MBI-GS (43). The MBI-GS consists of 15 items and taps three subscales, namely exhaustion ( 5 items, for example, "I feel mentally exhausted because of my work"; $\alpha=0.93$ ), cynicism (four items, for example, "I doubt the significance of my work"; $\alpha=0.85$ ), and professional efficacy (6 items, for example, "I can effectively solve the problems that arise in my work"; $\alpha=0.83$ ), which are scored on a 7-point scale ranging from 0 (never) to 6 (everyday).

Work engagement was measured with the UWES (3, 40). The UWES includes 17 items that are indicative of three dimensions, namely, vigor (6 items, for example, "At work, I feel full of energy"; $\alpha=0.88$ ), dedication (5 items, for example, "I am enthusiastic about my job"; $\alpha=0.94$ ), and absorption (6 items, for example, "When I am working, I forget everything else around me"; $\alpha=0.74$ ), which are scored on a 7-point scale ranging from 0 (never) to 6 (everyday).

Table 1. Demographic variables for the burned-out, engaged, and reference group.

\begin{tabular}{|c|c|c|c|c|c|c|c|c|c|c|c|c|}
\hline \multirow[t]{2}{*}{ Group } & \multicolumn{2}{|c|}{$\begin{array}{c}\text { Age } \\
\text { (years) }\end{array}$} & \multicolumn{2}{|c|}{$\begin{array}{c}\text { Organizational } \\
\text { tenure } \\
\text { (years) }\end{array}$} & \multicolumn{2}{|c|}{$\begin{array}{l}\text { Contract } \\
\text { (hours/ } \\
\text { week) }\end{array}$} & \multirow{2}{*}{$\begin{array}{c}\text { Marital status } \\
\text { (percentage } \\
\text { married) } \\
(\%)\end{array}$} & \multicolumn{2}{|c|}{$\begin{array}{c}\text { Educational } \\
\text { level }(\%)\end{array}$} & \multirow[t]{2}{*}{$\begin{array}{c}\text { Smokers } \\
(\%)\end{array}$} & \multicolumn{2}{|c|}{$\begin{array}{c}\text { Body mass } \\
\text { index } \\
\left(\mathrm{kg} / \mathrm{m}^{2}\right)\end{array}$} \\
\hline & Mean & SD & Mean & SD & Mean & SD & & Secondary & College & & Mean & $\mathrm{SD}$ \\
\hline Burned-out ( $N=29)$ & 45.3 & 8.1 & 20.2 & 10.0 & 37.8 & 1.8 & 89.7 & 34.4 & 58.6 & 20.7 & 25.2 & 2.7 \\
\hline Engaged $(\mathrm{N}=33)$ & 45.1 & 7.9 & 20.4 & 12.3 & 38.6 & 1.9 & 97.0 & 33.4 & 60.6 & 15.6 & 25.2 & 2.1 \\
\hline Reference $(\mathrm{N}=26)$ & 42.9 & 7.7 & 18.9 & 12.3 & 38.7 & 1.5 & 73.1 & 42.3 & 46.1 & 16.0 & 26.2 & 3.5 \\
\hline
\end{tabular}




\section{Physiological measures}

Saliva was collected on three consecutive workdays and one nonworkday. For the cortisol analyses, saliva was sampled four times to determine the cortisol awakening response, immediately after awakening and 15, 30, and 60 minutes thereafter. The participants had to chew gently for about 60 seconds on cotton rolls, which were then put into plastic tubes (Sarstedt; Etten-Leur, Netherlands). In addition, the managers were instructed to take an oral dose of dexamethasone $(0.5 \mathrm{mg})$ on the second evening at 2230 to examine the dexamethasone-suppressed cortisol levels the next morning. For the DHEAS analysis, saliva was collected by passive drool (saliva is put into the plastic tube through a short plastic straw) 1 hour after awakening on the first two workdays and on the nonworkday. No cotton roles were used because they may have caused falsely high DHEAS values.

All of the managers were instructed to follow the time schedule strictly. They were asked to complete the sampling before breakfast and refrain from drinking coffee or tea and brushing their teeth. A short diary was filled out during the saliva collection. The managers reported the time of sampling, sleep quality, perceived and expected stress, physical activity, and food, drink and nicotine intake.

The managers stored their samples in a refrigerater $\left(\right.$ at $4^{\circ} \mathrm{C}$ ) until they finished their sampling schedule. When finished, they sent the samples back to the researchers by surface mail. All of the samples were stored in a freezer $\left(-20^{\circ} \mathrm{C}\right)$ until the analyses. Before free cortisol was assayed, the samples were thawed and spun at 3000 revolutions/minute for 5 minutes to obtain 0.51.0 milliliters of clear saliva with low viscosity. Cortisol was analyzed using an immunoassay (DELFIA) (44). For the used technique, the precision of the intra- and interassay variability was $2.9-7.7 \%$ and $6.2-11.5 \%$, respectively.

\section{Preliminary analyses}

A multivariate analysis of variance was used to test whether the three groups differed with respect to demographics and the psychological measures. The cortisol and DHEAS data were checked for missing values and outliers. Per sample point, cortisol, and DHEAS values that exceeded three standard deviations of the mean were excluded from further analysis (22). Missing values and outliers made up $3.2 \%$ and $1.6 \%$ of the dataset, respectively. All of the data were checked for skewness, and, because of a nonnormal distribution, a logarithmic transformation was applied to the cortisol values on the day of the dexamethasone suppression and to all of the DHEAS values. Within-person cortisol values can show some variation over days. To get a more reliable indication of cortisol as a subject characteristic, the values of the two workdays were pooled for the analysis. For each day, the cortisol: DHEAS ratio was calculated as follows: first, the total amount of morning cortisol within 1 hour after awakening, called area under the curve (AUC ground) (45), was calculated; then, the AUC-ground values were divided by the DHEAS values. This ratio appeared to have a nonnormal distribution and was thus normalized using a $\log (\mathrm{x}+1)$ transformation.

\section{Cortisol and dehydroepiandrosterone-sulfate analyses}

First, a repeated-measure analysis with the "within factors" time $(0,15,30$, and 60 minutes after awakening) and day (workday and nonworkday), and the "between factor" group (burned-out, work-engaged, and reference) was used to test the cortisol morning level and cortisol awakening response. Second, another repeatedmeasures analysis was applied in which people with a negative cortisol increase in the first 30 minutes after awakening (AUC increase) (45) were excluded. A negative cortisol increase is indicative of noncompliance (46, 47), usually caused by a delay between the wake-up time and sampling time $(14,48)$, the result, in this case, being the exclusion of 6 managers in the burned-out group, 4 in the work-engaged group, and 4 in the reference group on the workday and 7 burned-out, 13 work-engaged and 11 reference managers on the nonworkday.

To test cortisol suppression the day after dexamethasone intake, a repeated-measures analysis with time as the "within factor" and group as the "between factor" was used. Five managers refrained from dexamethasone intake, of which one was in the burned-out group, one was in the work-engaged group, and three were in the reference group. When the repeated-measures analysis revealed significant effects, posthoc tests were used to specify the effects. Finally, multivariate analyses of variance were used to test possible differences between the groups on the workdays and the nonworkday with regard to the DHEAS values and the cortisol: DHEAS ratio.

\section{Results}

\section{Descriptives}

The correlations between burnout and work engagement are presented in table 2 .

The mean scores and standard deviations (SD) of the three groups on the psychological measures are shown in table 3. The groups did not differ from each other with regard to demographics, the number of slept hours, and the time of awakening. As is obvious, the groups 
differed strongly from each other with regard to all of the psychological measures, multivariate $\mathrm{F}(\mathrm{df}=12$, $162)=22.65, \mathrm{P}<0.001$. Subsequent univariate tests showed significant differences on all of the subscales of the psychological measures. Specifically, and as can be deduced from table 3, Bonferroni posthoc tests showed that the burned-out group scored significantly and substantially higher on exhaustion and cynicism than the two other groups and lower on professional efficacy, vigor, and dedication. The work-engaged group scored higher on all of the work engagement scales than the two other groups.

\section{Morning cortisol level and the cortisol awakening response}

Figure 1 shows the morning cortisol levels of the three groups in the first hour after awakening on the workday and the nonworkday. A significant main effect was found for time, $\mathrm{F}(3,79)=49.24, \mathrm{P}<0.001$, indicating that there was a cortisol awakening response in the first hour after awakening across days. The main effect of day was also significant, $\mathrm{F}(1,81)=68.77, \mathrm{P}<0.001$, reflecting that morning cortisol levels were higher on the workdays than on the nonworkday. However, the main group effect (between participants) was not significant, $\mathrm{F}(2,81)=1.25, \mathrm{P}=0.29$; thus the three groups
Table 2. Pearson correlations between burnout and work engagement. All of the correlations are significant at the $P<0.01$ level. (MBI-GS = Maslach Burnout Inventory-General Survey, UWES = Utrecht Work Engagement Scale)

\begin{tabular}{lrrrrr}
\hline & 1 & 2 & 3 & 4 & 5 \\
\cline { 2 - 6 } & & & & & \\
Burnout (MBI-GS) & - & & & & \\
$\begin{array}{l}\text { 1. Exhaustion } \\
\text { 2. Cynicism }\end{array}$ & 0.77 & - & & & \\
3. Professional efficacy & -0.65 & -0.63 & - & & \\
Work Engagement (UWES) & & & & & \\
4. Vigor & -0.68 & -0.69 & 0.76 & - & \\
5. Dedication & -0.74 & -0.82 & 0.78 & 0.81 & - \\
6. Absorption & -0.34 & -0.45 & 0.40 & 0.68 & 0.54 \\
\hline
\end{tabular}

did not differ from each other with respect to morning cortisol across days. No significant day $\times$ group and time $\times$ group interactions were found either. In other words, neither on workdays nor on nonworkdays did the three groups differ from each other with regard to morning cortisol. The day $\times$ time interaction was significant, $\mathrm{F}(3,79)=3.46, \mathrm{P}=0.02$, indicating that there was a steeper slope for the cortisol awakening response on the workdays than on the nonworkday. The day $\times$ time $\times$ group interaction almost reached significance, $\mathrm{F}(6,160)=$ $1.85, \mathrm{P}=0.09$, indicating a trend for the groups to differ in slopes on the workdays and the nonworkday.

Table 3. Psychological measures for the burned-out, engaged, and reference group. (MBI-GS = Maslach Burnout Inventory-General Survey, UWES = Utrecht Work Engagement Scale, GSQS = Groningen Sleep Quality Scale)

\begin{tabular}{|c|c|c|c|c|c|c|c|}
\hline \multirow[t]{2}{*}{ Measure } & \multicolumn{2}{|c|}{ Burned-out (N=29) } & \multicolumn{2}{|c|}{ Engaged $(\mathrm{N}=33)$} & \multicolumn{2}{|c|}{ Reference $(\mathrm{N}=26)$} & \multirow[t]{2}{*}{ Univ $F$} \\
\hline & Mean & SD & Mean & SD & Mean & SD & \\
\hline \multicolumn{8}{|l|}{ Burnout (MBI-GS) a } \\
\hline Exhaustion ${ }^{b}$ & $2.9^{a}$ & 0.62 & 0.81 & 0.71 & 0.93 & 0.98 & 67.95 \\
\hline Cynicism ${ }^{b}$ & $2.5^{\mathrm{a}}$ & 0.73 & 0.39 & 0.46 & 0.50 & 0.47 & 133.89 \\
\hline Professional efficacy ${ }^{b}$ & $3.6^{\mathrm{a}}$ & 0.74 & 5.0 & 0.51 & 4.6 & 0.57 & 40.17 \\
\hline \multicolumn{8}{|c|}{ Work Engagement (UWES) } \\
\hline Vigor $^{c}$ & $3.4^{\mathrm{a}}$ & 0.69 & 5.2 & 0.36 & $4.4^{c}$ & 0.62 & 84.60 \\
\hline Dedication $^{d}$ & $3.3^{\mathrm{a}}$ & 0.82 & 5.4 & 0.40 & 4.7 & 0.68 & 84.69 \\
\hline Absorption b & $3.3^{\mathrm{a}}$ & 0.75 & 4.7 & 0.40 & 3.4 & 0.64 & 49.50 \\
\hline \multicolumn{8}{|l|}{ Sleep quality (GSQS) ${ }^{\text {e }}$} \\
\hline Workdays & $4.38^{a}$ & 2.26 & 2.04 & 1.68 & 1.86 & 1.13 & 19.29 \\
\hline Nonworkday & $3.14^{\mathrm{a}}$ & 2.71 & 1.09 & 1.31 & 1.15 & 1.59 & 10.27 \\
\hline \multicolumn{8}{|c|}{ Amount of sleep (hours:min) } \\
\hline Workdays & $7: 24$ & $0: 52$ & $6: 58$ & $0: 44$ & $6: 57$ & $0: 35$ & .. \\
\hline Nonworkday & $8: 49$ & $1: 13$ & $8: 24$ & $1: 08$ & $8: 07$ & $1: 06$ & .. \\
\hline \multicolumn{8}{|l|}{ Time of awakening } \\
\hline Workdays & 0631 & $0: 47^{f}$ & 0631 & $0: 26^{f}$ & 0621 & $0: 25^{f}$ & .. \\
\hline Nonworkday & 0824 & $1: 32^{f}$ & 0844 & $1: 06^{f}$ & 0830 & $0: 55^{f}$ & .. \\
\hline
\end{tabular}

${ }^{a}$ Burnout and work engagement were measured on 7-point scales ranging from 0 (never) to 6 (everyday).

${ }^{\mathrm{b}}$ The engaged and reference group differed significantly from the burned-out group at the $\mathrm{P}<0.01$ level but did not differ from each other.

c The burned-out, engaged and reference groups differed significantly from each other at the $P<0.001$ level.

d The engaged group differed significantly from the burned-out and reference groups at the $\mathrm{P}<0.001$ level, but the burned out and reference groups did not differ from each other.

e Sleep quality ranged from 0 (good sleep quality) to 14 (bad sleep quality).

Standard deviation in number of hours and minutes (hours:minutes). 

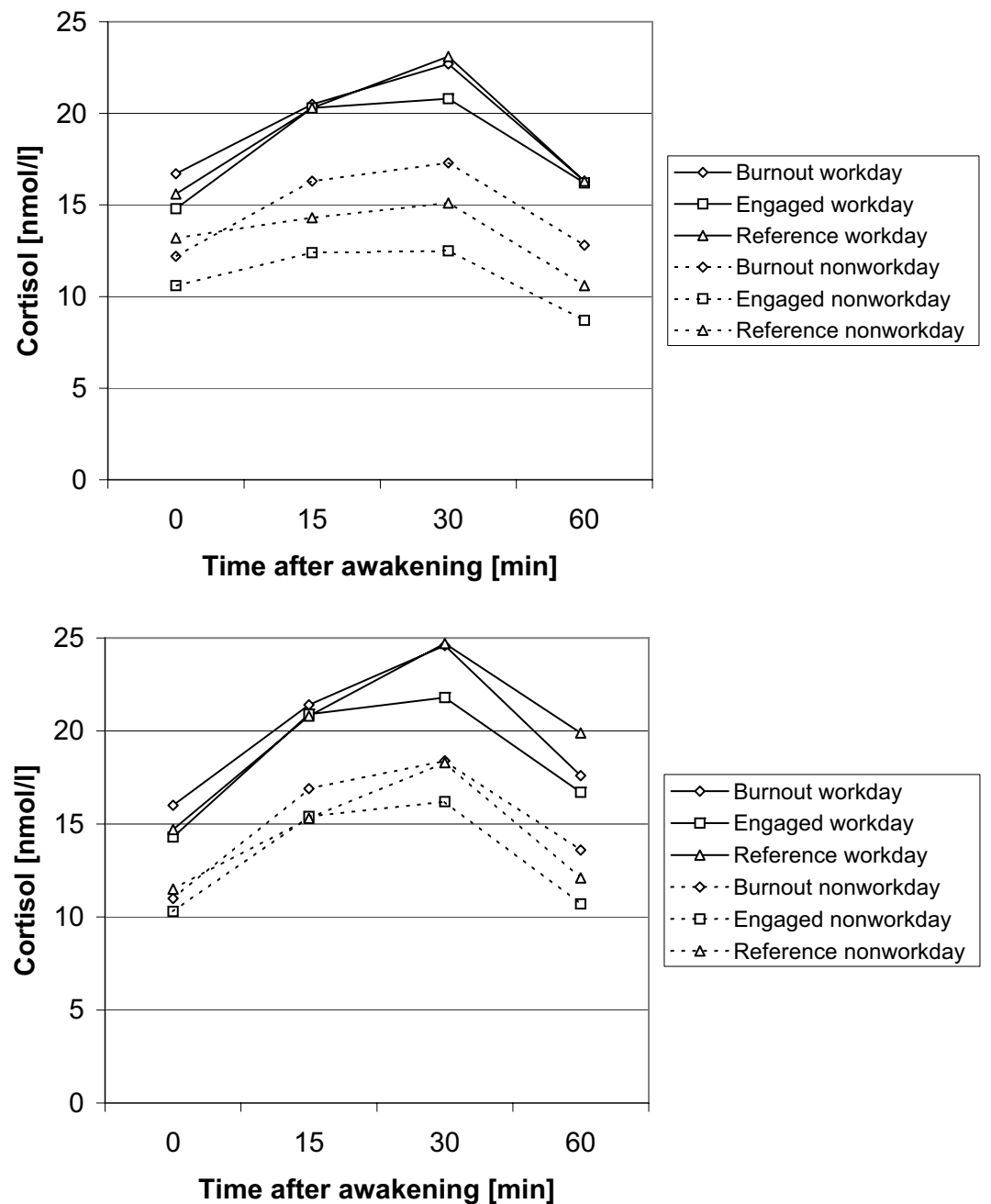

Figure 1. Cortisol awakening response on a workday and nonworkday, all managers included. Note: the burned-out, work-engaged, and reference groups consisted of 29,33 , and 26 managers, respectively.
Figure 2. Cortisol awakening response on a workday and nonworkday, excluding the managers with a negative AUC increase. Note: the burned-out, work-engaged, and reference groups consisted of 18, 19, and 12 managers, respectively.
To substantiate these results, analyses were rerun excluding the managers with a negative AUC increase in the first 30 minutes after awakening. The morning cortisol levels and slopes of the three groups, on the workdays and the nonworkday, are shown in figure 2. Consistent with the previous analysis, a significant main effect was found for time, $\mathrm{F}(3,41)=62.34, \mathrm{P}<0.001$, and day, $\mathrm{F}(1,43)=30.13, \mathrm{P}<0.001$, indicating that there was a cortisol awakening response in the first hour after awakening across days and that the cortisol levels were higher on the workdays than on the nonworkday. Again, the main group effect was not significant. In addition, none of the interaction effects was significant. Thus in contrast to the result of the previous analysis, the increase of the cortisol awakening response was the same on the workdays as on the nonworkday.

\section{Feedback sensitivity: the effect of dexamethasone sup- pression}

Figure 3 shows the morning cortisol levels of the three groups in the first hour after awakening on the day after the dexamethasone intake. The main effect of time, and the time $\times$ group interaction were not significant. Thus, as expected, there was no overall increase in cortisol after awakening. The burned-out, work-engaged, and reference managers did not differ from each other with regard to cortisol increase. However, the group main effect was significant $[\mathrm{F}(2,76)=3.43, \mathrm{P}=0.04]$, and therefore the groups showed different levels of cortisol on this day. Bonferroni posthoc tests revealed that this effect was due to the lower cortisol levels of the work-engaged employees at 15 and 30 minutes after awakening.

\section{Dehydroepiandrosterone-sulfate levels and the cortisol: dehydroepinandrosterone sulfate ratio}

The means and standard deviations of the three groups are shown in table 4 for DHEAS. The groups did not differ from each other with regard to their DHEAS levels, either on the workdays or on the nonworkday [multivariate $\mathrm{F}(\mathrm{df}=6,158)=1.02$, not significant]. Furthermore, no significant differences were found between 


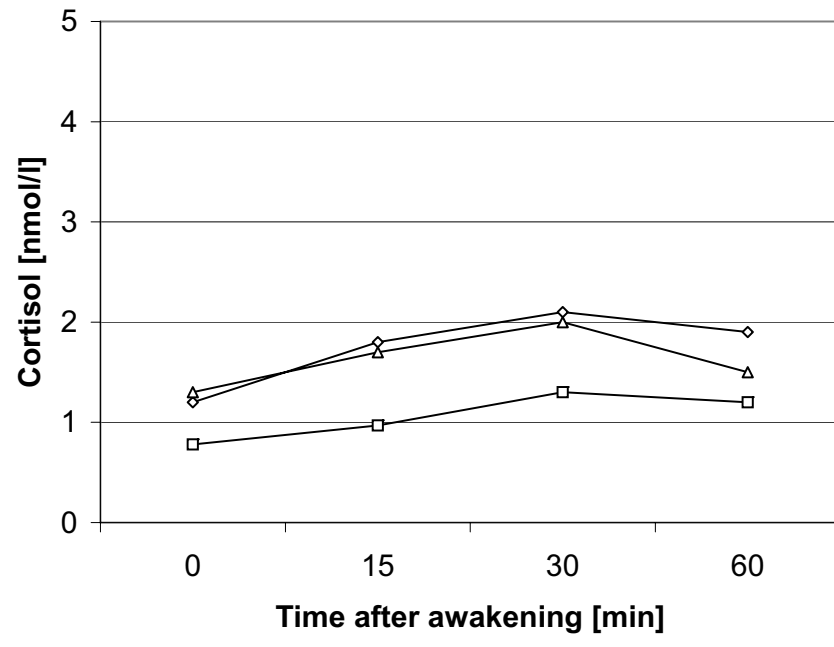

the three groups with regard to the cortisol: DHEAS ratio on any of these days [multivariate $\mathrm{F}(\mathrm{df}=6,148)=$ 0.89 , not significant].

\section{Discussion}

The overall picture of HPA-axis functioning in stressrelated disorders is confusing - both hypo- and hyperfunction of the HPA axis has been reported $(12,16,18-$ $21,23,25)$. The idea behind our study was that studying the opposite poles of work-related well-being (burnout and work engagement) would create enough contrast to find differences in HPA-axis functioning. According to the results, the burned-out, work-engaged, and reference group did, however, not differ with respect to morning cortisol levels, the cortisol awakening response, the DHEAS levels, or the cortisol: DHEAS ratio. Although the morning cortisol levels were higher on the workdays than on the nonworkday, this effect did not differ between the groups. The only difference was a stronger cortisol suppression in the work-engaged group in response to the low-dose dexamethasone suppression test.

Our results with respect to cortisol morning levels and the cortisol awakening response in burnout were in agreement with those of Grossi et al $(18,19)$, Mommersteeg et al (22), and Steptoe et al (24), who reported no deviations in the cortisol levels of burned-out employees, burnout patients, and people confronted with high job strain, respectively. Grossi et al (19) only reported elevated morning cortisol levels in female burnout patients on sick leave. Women with a high burnout score, but not on sick leave, and men (either patients or men with a high burnout score but not on sick leave) did not differ from healthy people.

Furthermore, our findings are in contrast with Melamed et al (20), who reported elevated morning

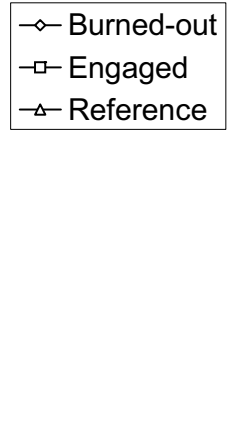

Figure 3. Cortisol awakening response after dexamethsaone intake in the burned-out, work-engaged and reference groups. Note: The burnout, work-engaged, and reference groups consisted of 26,31 , and 22 managers, respectively.
Table 4. Means and standard deviations for the burned-out, work-engaged, and reference groups as regards the dehydroepiandrosterone-sulfate (DHEAS) levels.

\begin{tabular}{|c|c|c|c|c|c|c|}
\hline \multirow[t]{2}{*}{ Group } & \multicolumn{2}{|c|}{ Workday 1} & \multicolumn{2}{|c|}{ Workday 2} & \multicolumn{2}{|c|}{ Nonworkday } \\
\hline & Mean & SD & Mean & SD & Mean & SD \\
\hline Burned-out ( $N=29)$ & 4.14 & 4.19 & 3.50 & 3.03 & 3.14 & 3.91 \\
\hline Engaged ( $\mathrm{N}=33$ ) & 3.43 & 3.69 & 2.68 & 2.68 & 2.38 & 2.46 \\
\hline Reference $(\mathrm{N}=26)$ & 3.25 & 2.80 & 4.07 & 3.94 & 2.62 & 1.93 \\
\hline
\end{tabular}

cortisol levels for employees with a high burnout score. However, the assessment of morning cortisol levels in the study of Melamed et al was only based on one sample, taken at 0800 , and it does not provide any insight into the awakening response. Higher morning cortisol levels, but no difference in the increase, have also been reported by De Vente et al (17), for burnout patients. In addition, Pruessner et al (23) also reported no differences in the cortisol awakening response among employees with a high burnout score, but lowered cortisol levels in the first hour after awakening. It is important to note that the high and low burnout groups in the study of Pruessner et al were defined on the basis of median split of burnout scores and not on the basis of validated cut-off scores (as in our study). Consequently, the groups in Pruessner et al's study were less extreme (and showed fewer differences regarding burnout symptoms) than the groups in our study. This finding makes it all the more remarkable that differences were found. Lowered cortisol secretion in burnout has also been reported by Moch et al (21), but this finding was based on 24-hour urine cortisol collection, and only 16 female patients were included. On the basis of our findings and those of earlier studies, we conclude that, despite some isolated differences, there is no convincing evidence for abnormalities in HPA-axis functioning in burnout.

HPA-axis functioning also appeared to be normal among work-engaged employees. We did not find lower 
cortisol levels, as sometimes found in studies that focused on the association of positive well-being (27) and positive affect $(28,29)$ with cortisol. In addition, we did not find anomalies in the increase in cortisol in the first hour after awakening. This was the first study to date that included two opposite psychological states, creating a strong contrast. Nevertheless, our sensitive design did not provide evidence for deviations in HPA-axis functioning in burnout vis-à-vis work engagement.

The dexamethasone suppression test, however, yielded an interesting finding, a stronger dexamethasone suppression of the work-engaged managers. The extent to which cortisol release is inhibited after dexamethasone intake indicates feedback sensitivity; thus we can conclude that work-engaged managers have a more sensitive HPA-feedback function. Interestingly, high feedback efficiency is usually observed in concordance with, and considered to be a cause of, lower overall cortisol levels (49). Indeed the work-engaged group in our study consistently showed the lowest morning cortisol levels, although the difference from the other groups was not significant. We observed no deviant cortisol suppression in the dexamethasone suppression test in the burned-out group, and this finding is in agreement with the recent findings of Mommersteeg et al (22). However, Pruessner et al (23) has reported that burned-out participants had lower levels of cortisol after dexamethasone intake. In this case, the lower cortisol levels after dexamethasone intake may have reflected the lower cortisol level they observed in general in the burnout group, instead of hypersuppression.

In all three groups, the morning cortisol levels were higher on the workdays than on the nonworkday, consistent with findings reported by Schlotz et al (50). Furthermore, at first sight, the increase in cortisol in the first 30 minutes after awakening appeared to be greater on the workdays than on the nonworkday, consistent with findings of earlier studies $(14,50)$. This finding would support the interpretation of the cortisol awakening response as an indicator of anticipation to activities of the workday (14). However, the latter result needs to be interpreted with caution because it disappeared when we excluded negative cortisol awakening responses that probably indicate noncompliance to the prescribed time schedule. Remarkably, in the study of Kunz-Ebrecht et al (14), the effect remained present after noncompliers (people who reported more than 10 minutes delay between wake up time and sampling time) were excluded. However, in this study, only two morning samples were examined, on only one workday, which resulted in a limited reliability considering intraindividual variation between days.

We observed no differences between the three groups with regard to their DHEAS levels and the cortisol: DHEAS ratio, either on the workdays or on the nonworkday. These results do not support earlier findings that higher levels of DHEA(S) are positively associated with a positive affect (32), positive well-being, and better physical and mental health (33), and negatively associated with depression $(34,35)$ and with chronic fatigue syndrome (35-37). Nor did Grossi et al (18) report any deviations in DHEAS in participants with a high burnout score. Therefore, we tend to conclude that there is no change in metabolic balance (cortisol: DHEAS ratio) in burnout or work engagement.

Recently, negative results with regard to HPA-axis functioning in burnout have been more often reported and could lead to the conclusion that the role of the HPA axis in the long-term effects of stress on psychological well-being is more complex than initially thought. It has also recently been concluded that endocrinological and self-report strain measures do not substitute for each other, but may reflect different underlying processes or different aspects of stress responses (51). Furthermore, the physiological system is presumably able to compensate itself on several levels in the axis. To reveal more subtle disregulations in the future, more sensitive measurement techniques may be needed, like the combined dexamethasone/corticotropin-releasing hormone test or tests with infusion of the corticotropin-releasing hormone and the adrenocorticotropic hormone.

\section{Limitations}

A limitation of this study was the relatively small size of the group, the more so after those with a negative AUC increase were eliminated. The elimination needed to be made to correct for noncompliance. For compliance to be enhanced, it is advisable to use eDEM ${ }^{\mathrm{TM}}$ (Aardex Ltd, Zug, Switzerland) electronic monitoring caps, through which exact sampling time can be registered (47). A credit to our study was the selection of extreme groups, on the basis of validated burnout and work engagement scores. As could be expected, the burned-out, work-engaged, and reference groups differed strongly from each other on the burnout and work engagement measures. It should be noted, however, that the mean exhaustion score in our burned-out group was 2.9, which corresponded with the scoring anchor "regularly". Thus, compared with both of the other groups, the burned-out group reported relatively more symptoms of exhaustion. However, this finding does not necessarily mean that the burned-out managers in the current study experienced extremely high burnout levels in absolute terms.

\section{Concluding remarks}

In summary, our study documents that burnout and work engagement cannot be distinguished with regard to 
HPA-axis functioning, at least not with the techniques that we used. The basal cortisol levels did not differ between the groups, although the work-engaged employees showed a better cortisol suppression in response to dexamethasone, this finding indicating a higher feedback sensitivity for the HPA axis. Although the latter result needs replication in future studies, our study indicates that the robustness of the HPA axis as a stressregulating system has been underestimated.

\section{References}

1. Demerouti E, Bakker AB, de Jonge J, Janssen PPM, Schaufeli WB. Burnout and engagement at work as a function of demands and control. Scand J Work Environ Health. 2001; 27(4):279-86.

2. Schaufeli WB, Bakker AB. Job demands, job resources and their relationship with burnout and engagement: a multi-sample study. J Organ Behav. 2004;25:293-315.

3. Schaufeli WB, Salanova M, Gonzalez-Roma V, Bakker AB. The measurement of engagement and burnout: a two sample confirmatory analytic approach. J Happiness Stud. 2002;3:7192.

4. Halbesleben JRB, Buckley MR. Burnout in organizational life. J Manage. 2004;30:859-79.

5. Maslach C, Schaufeli WB, Leiter MP. Job burnout. Annu Rev Psychol. 2001;52:397-422.

6. González-Romá V, Schaufeli WB, Bakker AB, Lloret S. Burnout and work engagement: Independent factors or opposite poles? J Vocat Behav. 2006;68:165-74.

7. Appels A, Schouten EGW. Burnout as a risk factor for coronary heart disease. Behav Med. 1991;17:53-9.

8. Mohren DCL, Swaen GMH, Kant IJ, van Amelsfoort LGPM, Borm PJA, Galama JMD. Common infections and the role of burnout in a Dutch working population. J Psychosom Res. 2003;55:201-8.

9. Shirom A, Melamed S, Toker S, Berliner S, Shapira I. Burnout and health review: current knowledge and future research directions In: Hodgkinson GP, Ford JK, editors. International review of industrial and organizational psychology; vol 20. Chichester (UK): Wiley; 2005. p 269-309.

10. Nicolson N, van Diest R. Salivary cortisol patterns in vital exhaustion. J Psychosom Res. 2000;49:335-43.

11. Demitrack M. Neuroendocrine correlates of chronic fatigue syndrome: a brief review. J Psychiatr Res. 1997;31(1):69-82.

12. Ehlert U, Gaab J, Heinrichs M. Psychoneuroendocrinological contributions to the etiology of depression, posttraumatic stress disorder and stress-related bodily disorders: the role of the hypothalamus-pituitary-adrenal axis. Biol Psychol. 2001;57:141-52.

13. Schmidt-Reinwald A, Pruessner JC, Hellhammer DH, Federenko I, Rohleder N, Schurmeyer TH, et al. The cortisol response to awakening in relation to different challenge tests and a 12-hour cortisol rhythm. Life Sci. 1999;64:1653-60.

14. Kunz-Ebrecht SR, Kirschbaum C, Marmot M, Steptoe A. Differences in cortisol awakening response on work days and weekends in women and men from the Whitehall II cohort. Psychoneuroendocrinology. 2004;29:516-28.

15. Lundberg U, Hellström B. Workload and morning salivary cortisol in women. Work Stress. 2002;16:356-63.
16. Schulz P, Kirschbaum C, Pruessner JC Hellhammer DH. Increased free cortisol secretion after awakening in chronically stressed individuals due to work overload. Stress Med. 1998;14:91-7.

17. de Vente W, Olff M, van Amsterdam JGC, Kamphuis JH, Emmelkamp PMG. Physiological differences between burnout patients and healthy controls: blood pressure, heart rate, and cortisol responses. Occup Environ Med. 2003;60 suppl I:i54-i61.

18. Grossi G, Perski A, Evengard B, Blomkvist V, Orth-Gomer K. Physiological correlates of burnout among women. J Psychosom Res. 2003;55:309-16.

19. Grossi G, Perski A, Ekstedt M, Johansson T, Lindström M, Holm K. The morning salivary cortisol response in burnout. J Psychosom Res. 2005;59:103-11.

20. Melamed S, Ugarten U, Shirom A, Kahana L, Lerman Y, Froom P. Chronic burnout, somatic arousal and elevated salivary levels. J Psychosom Res. 1999;46:591-8.

21. Moch SL, Panz VR, Joffe BI, Havlik I, Moch JD. Longitudinal changes in pituitary-adrenal hormones in South African women with burnout. Endocrine. 2003;21:267-72.

22. Mommersteeg PMC, Heijnen CJ, Verbraak MJPM, van Doornen LJP. Clinical burnout is not reflected in the cortisol awakening response, the day-curve or the response to a lowdose dexamethasone suppression test. Psychoneuroendocrinology. 2006;31:216-25.

23. Pruessner J, Hellhammer DH, Kirschbaum C. Burnout, perceived stress and salivary cortisol upon awakening. Psychosom Med. 1999;61:197-204.

24. Steptoe A, Cropley M, Griffith J, Kirschbaum C. Job strain and anger expression predict early morning elevations in salivary cortisol. Psychosom Med. 2000;62:286-192.

25. Mommersteeg PMC, Keijsers GPJ, Heijnen CJ, Verbraak MJPM, van Doornen LJP. Cortisol deviations in people with burnout before and after psychotherapy; a pilot study. Health Psychol. 2006;25:243-8

26. Heim C, Ehlert U, Hellhammer DH. The potential role of hypocortisolism in the pathophysiology of stress-related bodily disorders. Psychoneuroendocrinology. 2000;25:1-35.

27. Lindfors P, Lundberg U. Is low cortisol release an indicator of positive health? Stress Health. 2002;18:153-60.

28. Polk DE, Cohen S, Doyle WJ, Skoner DP, Kirschbaum C. State and trait affect as predictors of salivary cortisol in healthy adults. Psychoneuroendocrinology. 2005;30:261-72.

29. Smyth J, Ockenfels C, Porter L, Kirschbaum C, Hellhammer DH, Stone AA. Stressors and mood measured on a momentary basis are associated with salivary cortisol secretion. Psychoneuroendocrinology. 1998;23:353-70.

30. Cole MA, Kim PJ, Kalman BA, Spencer RL. Dexamethasone suppression of corticosteroid secretion: evaluation of the site of action by receptor measures and functional studies. Psychoneuroendocrinology. 2000;25:151-67.

31. Wolf OT, Kirschbaum C. Actions of dehydroepiandrosterone and its sulphate in the central nervous system: effects on cognition and emotion in animals and humans. Brain Res Brain Res Rev. 1999;30:264-88.

32. McCraty R, Barrios-Choplin B, Rozman D, Atkinson M, Watkins AD. The impact of a new emotional self-management program on stress, emotions, heart rate variability, DHEA and cortisol. Integr Physiol Behav Sci. 1998;33:151-70.

33. Barrett-Connor E, Khaw KT, Yen SS. A prospective study of dehydroepiandrosterone sulfate, mortality and cardiovascular disease. N Engl J Med. 1986;315:1519-24.

34. Barrett-Connor E, Von Muhlen D, Laughlin GA, Kripke A. 
Endogenous levels of dehydroepiandrosterone sulfate, but not other sex hormones, are associated with depressed mood in older women: The Rancho Bernardo Study. J Am Geriatr Soc. 1999;47:685-91.

35. Scott LV, Salahuddin F, Cooney J, Svec F, Dinan TG. Differences in adrenal steroid profile in chronic fatigue syndrome, in depression and in health. J Affect Disord. 1999;54:129-37.

36. Kuratsune H, Yamaguti K, Sawada M, Kodate S, Machii T, Kanakura Y, et al. Dehydroepiandrosterone sulfate deficiency in chronic fatigue syndrome. Int J Mol Med. 1998;1:143-6.

37. Van Rensburg SJ, Potocnik FC, Kiss T, Hugo F, van Zijl P, Mansvelt E, et al. Serum concentrations of some metals and steroids in patients with chronic fatigue syndrome with reference to neurological and cognitive abnormalities. Brain Res Bull. 2001;55:319-25.

38. Hechter O, Grossman A, Chatterton RT Jr. Relationship of dehydroepiandrosterone and cortisol in disease. Med Hypotheses. 1997;49:85-91.

39. Parker LN, Levin E, Lifrak E. Evidence for adrenocortical adaptation to severe stress. J Clin Endocrinol Metab. 1985;60:947-52.

40. Schaufeli WB, Bakker AB. Utrechtse Bevlogenheidschaal: Voorlopige Handleiding [The Utrecht Work Engagement Scale: manual]. Utrecht (Netherlands): Department of Social \& Organizational Psychology; 2003.

41. Schaufeli WB, van Dierendonck D. Handleiding van de Utrechtse Burnout Schaal (UBOS) [Manual Utrecht Burnout Scale]. Lisse (Netherlands): Swets \& Zeitlinger; 2000.

42. Brenninkmeijer V, van Yperen N. How to conduct research on burnout: advantages and disadvantages of a unidimensional approach to burnout. Occup Environ Med. 2003;60 suppl I:i16-i21.

43. Schaufeli WB, Leiter MP, Maslach C, Jackson SE. Maslach burnout inventory-general survey. In: Maslach C, Jackson SE, Leiter MP, editors. The Maslach burnout inventory-test manual. 3rd ed. Palo Alto (CA): Consulting Psychologists Press; 1996.

44. Dressendörfer RA, Kirschbaum C, Rohde W, Stahl F, Stras- burger CJ. Synthesis of a cortisol-biotin conjugate and evaluation as a tracer in an immunoassay for salivary cortisol measurement. J Steroid Biochem Mol Biol. 1992;43:683-92.

45. Pruessner JC, Kirschbaum C, Meinlschmid G, Hellhammer DH. Two formulas for computation of the area under the curve represent measures of total hormone concentration versus time-dependent change. Psychoneuroendocrinology. 2003;28:916-31.

46. Kudielka BM, Broderick JE, Kirschbaum C. Compliance with saliva sampling protocols: electronic monitoring reveals invalid cortisol daytime profiles in noncompliant subjects. Psychosom Med. 2003;65:313-9.

47. Broderick JE, Arnold D, Kudielka BM, Kirschbaum C. Saliva cortisol sampling compliance: comparison of patients and healthy volunteers. Psychoneuroendocrinology. 2004;29:63650 .

48. Kupper N, De Geus EJC, Van Den Berg M, Kirschbaum C, Boomsma DI, Willemsen G. Familial influences on basal salivary cortisol in an adult population. Psychoneuroendocrinology. 2005;30:857-68.

49. Huizenga NATM, Koper JW, de Lange P, Pols HAP, Stolk $\mathrm{RP}$, Grobbee DE, et al. Interperson variability but intraperson stability of baseline plasma cortisol concentrations, and its relation to feedback sensitivity of the hypothalamo-pituitaryadrenal axis to a low dose of dexamethasone in elderly individuals. J Clin Endocrinol Metab. 1998;83:47-54.

50. Schlotz W, Hellhammer J, Schulz P, Stone AA. Perceived work overload and chronic worrying predict weekend-weekday differences in the cortisol awakening response. Psychosom Med. 2004;66:207-14.

51. Sonnentag S, Fritz C. Endocrinological processes associated with job stress: catecholamine and cortisol responses to acute and chronic stressors. In: Perrewé PL, Ganster DC, editors. Research in organizational stress and well-being: employee health, coping, and methodologies. Amsterdam: Elsevier; 2006. p 1-59.

Received for publication: 28 November 2005 